\title{
Doenças fúngicas em cultivos de plantas ornamentais temperadas da região Agreste do Estado de Pernambuco, Brasil
}

\author{
Fungal diseases of temperate ornamentals cultivated in the \\ Agreste region of Pernambuco State, Brazil
}

Regina Ceres Torres da Rosa ${ }^{*}$, Tereza Cristina de Assis², Luciana Melo Sartori Gurgel ${ }^{1}$, Domingos Eduardo Guimarães Tavares de Andrade ${ }^{3}$, Eline Waked Ferreira Gomes ${ }^{4}$, Ana Patrícia dos Santos Gonçalves²

'Laboratôrio de Patologia de Sementes, Instituto Agronômico de Pernambuco (IPA), Av. General San Martin, 1371, Bongi, CEP 50761-000, Recife, PE, Brasil

${ }^{2}$ Laboratōrio de Fitopatologia, Instituto Agronômico de Pernambuco (IPA), Recife, PE, Brasil

${ }^{3}$ Laboratốrio de Fitopatologia, Estação Experimental de Itapirema, Instituto Agronômico de Pernambuco (IPA), Recife, PE, Brasil

${ }^{4}$ Departamento de Apoio Técnico e Científico, Instituto Agronômico de Pernambuco (IPA), Recife, PE, Brasil

*autor correspondente:

凶 reginactrosa@gmail.com
RESUMO: O interesse na produção e na comercialização de flores ornamentais temperadas vem crescendo a cada ano no Agreste Pernambucano, cujas condições edafoclimáticas existentes favorecem o seu cultivo. No entanto, a ocorrência de doenças é um dos principais fatores que limitam a produção de flores. Este estudo teve por objetivo identificar as doenças de plantas ornamentais temperadas causadas por fungos na região Agreste do Estado de Pernambuco. O levantamento das doenças foi realizado em 16 propriedades localizadas nos municípios de Gravatá, Chã Grande e São Vicente Ferrér. As amostras de diferentes plantas doentes foram levadas ao Laboratório de Fitopatologia (IPA), para isolamento e identificação dos fitopatógenos. Várias doenças importantes apresentaram alta incidência, com destaque para a pinta-pretada-roseira, a ferrugem-amarela do gladíolo, a ferrugem-branca do crisântemo, a ferrugem do tango, o mofo-branco e a mancha-de-cercospora em gérbera. A roseira e o crisântemo apresentaram maior diversidade fúngica, e o fungo Uromyces transversalis foi o mais frequente, seguido de Botrytis cinerea e Cladosporium sp.

PALAVRAS-CHAVE: Ocorrência, Rosa spp., Chrysanthemum spp., Gladiolus spp., Gerbera spp., fungos fitopatogênicos.
ABSTRACT: The interest in the production and marketing of temperate ornamental flowers has been growing steadily in the Agreste region of Pernambuco state, where the soil and climatic conditions favor their cultivation. However, the occurrence of diseases is one of the main limiting factors to the production of these flowers. This study aimed to identify diseases of temperate ornamental plants caused by fungi in the Agreste region of Pernambuco state. The survey of diseases was conducted in 16 properties in the municipalities of Gravatá, Chã Grande, and São Vicente Ferrér. Samples of different diseased plants were taken to the Laboratory of Plant Pathology (IPA) for isolation and identification of pathogens. Several important diseases showed high incidence, especially rose black spot, gladiolus rust, chrysanthemum white rust, goldenrod rust, white mold, and cercospora spot in Gerbera. Chrysanthemum and rose showed greater fungal diversity, whereas the fungus Uromyces transversalis was the most common, followed by Botrytis cinerea and Cladosporium sp. KEYWORDS: Occurrence, Rosa spp., Chrysanthemum spp., Gladiolus spp., Gerbera spp., phytopathogenic fungi.

O setor de produção e comercialização de flores e plantas ornamentais vem crescendo a cada ano no Brasil, sendo responsável por um número elevado de empregos fixos, com aproximadamente 194 mil empregos diretos; destes, 96.000 $(49,5 \%)$ estão relacionados à produção, $6.000(3,1 \%)$ à distribuição, $77.000(39,7 \%)$ ao comércio varejista e 15.000 $(7,7 \%)$, a outras funções, principalmente nos segmentos de apoio (INSTITUTO..., 2011). 
A condição de produção no Brasil, com uma ampla diversidade de solo e clima, permite o cultivo de grande número de espécies de comprovada qualidade e beleza, destacando-se as flores tropicais, os crisântemos, as rosas, as gérberas, as bromélias e os gerânios (LANDGRAF; PAIVA, 2009). No Nordeste, a produção de flores e plantas ornamentais concentra-se, principalmente, nos Estados de Pernambuco, Bahia, Ceará e Alagoas. Em Pernambuco, o cultivo de flores temperadas teve início na região agreste há cerca de 30 anos, onde a altitude e as condições edafoclimáticas existentes nas regiões serranas, com destaque para os municípios de Gravatá, Chã Grande e Garanhuns, favorecem a qualidade e o desenvolvimento das flores temperadas (MEDEIROS; FAVERO; PEDROSA FILHO, 2006; BRAINER; OLIVEIRA, 2007).

No entanto, um dos principais fatores que limitam a produção de flores é a ocorrência de diversas doenças de importância econômica, que ocasionam perdas significativas nas áreas de cultivo. O manejo inadequado da cultura contribui para o aumento da incidência e da severidade dos problemas fitossanitários, reduzindo a produtividade e/ou desvalorizando as flores para comercialização.

Na literatura, são apresentados vários gêneros de fungos e bactérias que prejudicam a produção e a qualidade das flores, ocasionando manchas foliares, murchas e podridões de colo e raiz (SANTOS, 2009; FREIRE; MOSCA, 2009; FERRONATO; LIMA NETO; TOMAZ, 2008). Em cultivos protegidos de gérbera (Gerbera jamesonii Bolos ex Hook), no Estado do Paraná, Ferronato et al. (2008) identificaram nove agentes causais de doença; destes, apenas um de natureza bacteriana (Pseudomonas cichorii Swingle) e todos os outros de natureza fúngica (Erysiphe cichoracearum DC. ex Merat, Pythium sp. Pringsheim, Phytophthora sp. De Bary, Fusarium oxysporum Schlecht., Cercospora gerberae Chupp \& Viegas, Botrytis cinerea Pers., Albugo tragopogonis (DC.) Gray., Capnodium sp. Mont). De acordo com Freire e Mosca (2009), o maior número de doenças é causado por fungos, os quais são mais frequentes durante o período chuvoso.

As medidas recomendadas para o controle destas doenças, como manejo de adubação, sistema de plantio e irrigação, muitas vezes não são efetivas e a aplicação de fungicidas químicos torna-se onerosa, além de provocar danos à saúde do homem e ao meio ambiente. Além disso, deve-se ressaltar que, na tentativa de solução destes problemas fitossanitários, vêm sendo utilizados produtos químicos sem prévia avaliação da eficiência e da adequação de uso.

A recomendação de medidas de controle e a elaboração de estratégias de manejo, assim como vários outros aspectos relacionados, dependem do conhecimento e da identificação dos problemas fitopatológicos existentes nas áreas produtoras, sendo, portanto, de fundamental importância a realização de levantamentos fitopatológicos. Desta forma, o presente trabalho tem por objetivo identificar as doenças de plantas ornamentais temperadas causadas por fungos, com a finalidade de obter informações para o estabelecimento de futuras estratégias de manejo dessas doenças nas áreas de produção.
A coleta das amostras foi realizada no período entre 2009 e 2010, em 16 propriedades de pequenos e médios produtores de plantas ornamentais temperadas dos municípios de Gravatá, Chã Grande e São Vicente Ferrér. Em cada área, foram coletadas amostras de diferentes partes de plantas doentes (caule, raiz, folhas e inflorescências), das seguintes culturas: rosa (Rosa spp. L.), smilax (Smilax sp. L.), lisiantus [(Eustoma grandiflorum (Raf.) Shinn.)], limonium (Limonium spp. Mill.), margaridinha (Bellis perennis L.), tango (Solidago canadensis L.), lírio (Lillium spp. L.), gérbera (Gerbera spp. L.), crisântemo (Chrysanthemum spp. L.) e gladíolo (Gladiolus spp. L.).

As amostras foram acondicionadas em sacos plásticos, devidamente identificados, e levadas ao Laboratório de Fitopatologia do Instituto Agronômico de Pernambuco - IPA, para o isolamento e a identificação dos fitopatógenos envolvidos nas doenças das plantas. A diagnose das doenças foi realizada inicialmente pela observação dos sintomas e sinais, com o auxílio de microscópio estereoscópico e ótico. Para as amostras cujos fitopatógenos não foram identificados diretamente, realizaram-se procedimentos laboratoriais para isolamento dos micro-organismos presentes nas partes doentes das plantas.

Após as etapas iniciais de limpeza e desinfestação do material, fragmentos da região de transição, entre a lesão e o tecido sadio (MENEZES; ASSIS, 2004), foram transferidos para placas de Petri contendo o meio de cultura BDA (batata, 200,0g; dextrose, 20,0g; agar, 17,0g; água destilada, 1L) suplementado com tetraciclina $(250 \mathrm{ppm})$, sendo então incubados a $25 \pm 2^{\circ} \mathrm{C}$, sob alternância luminosa (12 horas de claro/12 horas de escuro). Posteriormente, fragmentos do micélio de colônias, características dos fitopatógenos, foram transferidos para tubos contendo meio BDA e incubados nas mesmas condições anteriores. Para avaliar as características morfológicas do isolado do fitopatógeno, foi empregada a técnica de microcultura ou cultura em lâmina (MENEZES; ASSIS, 2004), sendo a incubação realizada durante 72 horas, sob as mesmas condições anteriores. Após esse período, as lamínulas foram removidas, montadas em lâminas coradas com azul de Amann, e examinadas ao microscópio ótico para observação das estruturas formadas. Os gêneros dos fungos foram identificados com base em suas características morfológicas e as espécies, com o auxílio de literatura específica (BARNETT; HUNTER, 1972; NELSON; TOUSSOUN; MARASAS, 1983; SIVANESAN, 1987; ALEXOPOULOS; MIMS; BLACKWELL, 1996).

Após a identificação, os isolados foram codificados, preservando-se as culturas puras em tubos de ensaio contendo meio BDA, sob refrigeração $\left(5^{\circ} \mathrm{C}\right)$ e, também, em água destilada esterilizada (MENEZES; ASSIS, 2004).

Associados ao material sintomático das diferentes plantas ornamentais temperadas, foram identificados os seguintes fungos: Diplocarpon rosae Wolf., Botrytis cinerea, Fusarium sp. Link ex Fr., F. oxysporum, F. solani (Mart.) Sacc., Phytophytora sp., Oidium sp. (Link) Sacc., Cercospora sp. Fuckel, Cladosporium sp. Link, Verticillium sp. Nees, Puccinia sp. Micheli, Puccinia horiana Henn, Uromyces transversalis 
sp. Micheli; Puccinia horiana Henn, Uromyces transversalis (Thüm.) Winter, Botrytis sp. Micheli, e Penicillium sp. Link (Tabela 1).

Neste estudo, foram abordados com mais detalhes os patógenos relevantes nas culturas de maior expressão econômica, tais como rosa, gladíolo, crisântemo, gérbera e tango, na Região Agreste de Pernambuco (Figura 1). $\mathrm{Na}$ Tabela 1, são apresentados os fungos fitopatogênicos encontrados em cada uma das culturas estudadas no presente levantamento. Em rosa e crisântemo, observou-se maior diversidade fúngica, enquanto que, em gladíolo e gérbera, não houve grande variação de espécies. Entretanto, em tango, foi verificada apenas a presença de Coleosporium sp.

Os gêneros e espécies fúngicas de maior ocorrência nas plantas ornamentais temperadas estudadas foram Uromyces transversalis, Botrytis cinerea, Cladosporium sp., Oidium sp. e Diplocarpon rosae, apresentando uma frequência de $20,0 \%$, $17,5 \%, 17,5 \%, 10,0 \%$ e 10,0\%, respectivamente (Figura 2).
$\mathrm{Na}$ cultura da roseira, destacaram-se as doenças: murcha de botões ou mofo das flores (Botrytis cinerea) e pinta-preta (Diplocarpon rosae). A ocorrência da murcha de botões é muito comum nesta cultura e geralmente ocorre em condições de alta umidade, pouca ventilação e baixas temperaturas $\left(16\right.$ a $\left.18^{\circ} \mathrm{C}\right)$. O fungo penetra nos tecidos jovens de flores e folhas, e desenvolvem inicialmente pequenas manchas marromaquosas, que evoluem rapidamente, cobrindo o órgão afetado com um crescimento pulverulento, que são as estruturas do fungo (PITTA, 1995). Nas áreas de cultivo de roseiras, foram observadas condições climáticas semelhantes às descritas por Pitta (1995), favorecendo o desenvolvimento e a severidade desta doença (Figura 3).

A pinta-preta é considerada uma das doenças mais disseminadas e prejudiciais ao cultivo de roseiras, chegando a impedir a produção de flores (MARCHANT et al. 1998). O surto da doença inicia-se a partir de respingos de chuva sobre os conídios, infectando novas folhas durante o período de cultivo.

Tabela 1. Fungos associados a doenças de plantas ornamentais temperadas, coletadas no Agreste do Estado de Pernambuco.

\begin{tabular}{ccc}
\hline Cultura & Nome científico & Fitopatógeno \\
\hline Rosa & Rosa spp. & Diplocarpon rosae \\
Botrytis cinerea & Cladosporium sp. \\
Oidium sp. & Fusarium oxysporum \\
& Fusarium solani
\end{tabular}

\begin{tabular}{|c|c|c|}
\hline Smilax & Smilax spp. & Fusarium oxysporum \\
\hline Lisiantus & Eustoma grandiflorum & $\begin{array}{c}\text { Cercospora sp. } \\
\text { Botrytis sp. }\end{array}$ \\
\hline Limonium & Limonium spp. & Verticillium sp. \\
\hline Margaridinha & Bellis perennis & Cladosporium sp. \\
\hline Tango & Solidago canadensis & Coleosporium sp. \\
\hline Lírio & Lillium spp. & $\begin{array}{c}\text { Fusarium oxysporum } \\
\text { Cladosporium } \mathrm{sp} . \\
\text { Cercospora } \mathrm{sp} .\end{array}$ \\
\hline Gérbera & Gerbera spp. & $\begin{array}{l}\text { Cercospora sp. } \\
\text { Stemphylium sp. } \\
\text { Oidium sp. } \\
\text { Cladosporium sp. }\end{array}$ \\
\hline Crisântemo & Chrysanthemum spp. & $\begin{array}{c}\text { Puccinia horiana } \\
\text { Stemphylium } \mathrm{sp} . \\
\text { Fusarium oxysporum } \mathrm{f} \text {. sp. chrysanthemi } \\
\text { Botrytis cinerea } \\
\text { Fusarium } \mathrm{sp} . \\
\text { Phytophytora } \mathrm{sp} .\end{array}$ \\
\hline Gladíolo & Gladiolus spp. & $\begin{array}{c}\text { Uromyces transversalis } \\
\text { Fusarium sp. } \\
\text { Penicillium gladioli }\end{array}$ \\
\hline
\end{tabular}




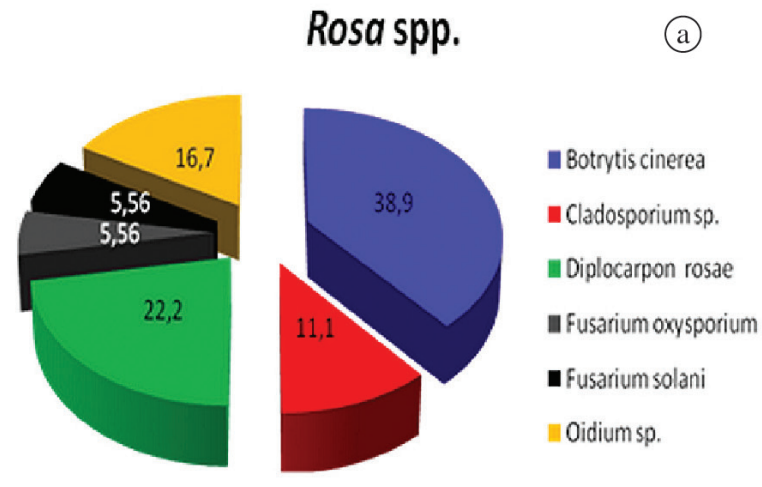

Chrysanthemum spp.

(b)

\section{Gladiolus spp.}

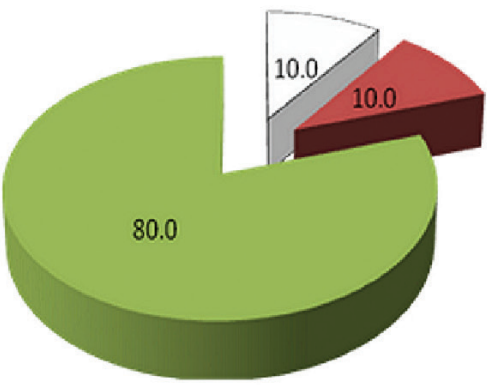

(c)
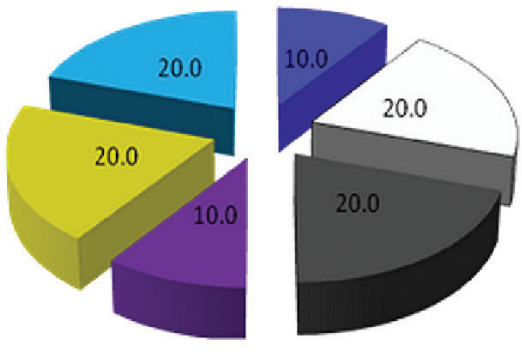

- Botrytis cinerea

口Fusarium sp.

-F.o. f. sp. Chrysanthemi

- Phytophytora sp.

a P. horiana

Intemphylium sp.

口Fusarium sp.

- Penicillium gladioli

Inromyces transversalis

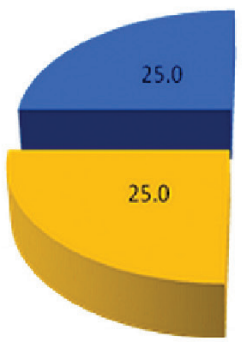

Gerbera spp.

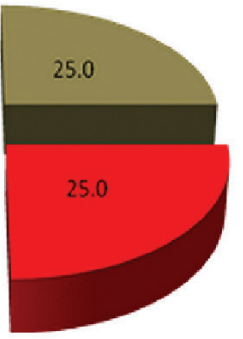

- Cercospora sp.

- Cladosporium $\mathrm{sp.}$

aidium sp.

= Stemphylium sp.

Figura 1. Incidência fúngica em plantas ornamentais de maior expressão econômica (a - Rosa spp.; b - Chrysanthemum spp.; c-Gladiolus spp.; d-Gerbera spp.) na Região Agreste pernambucana.

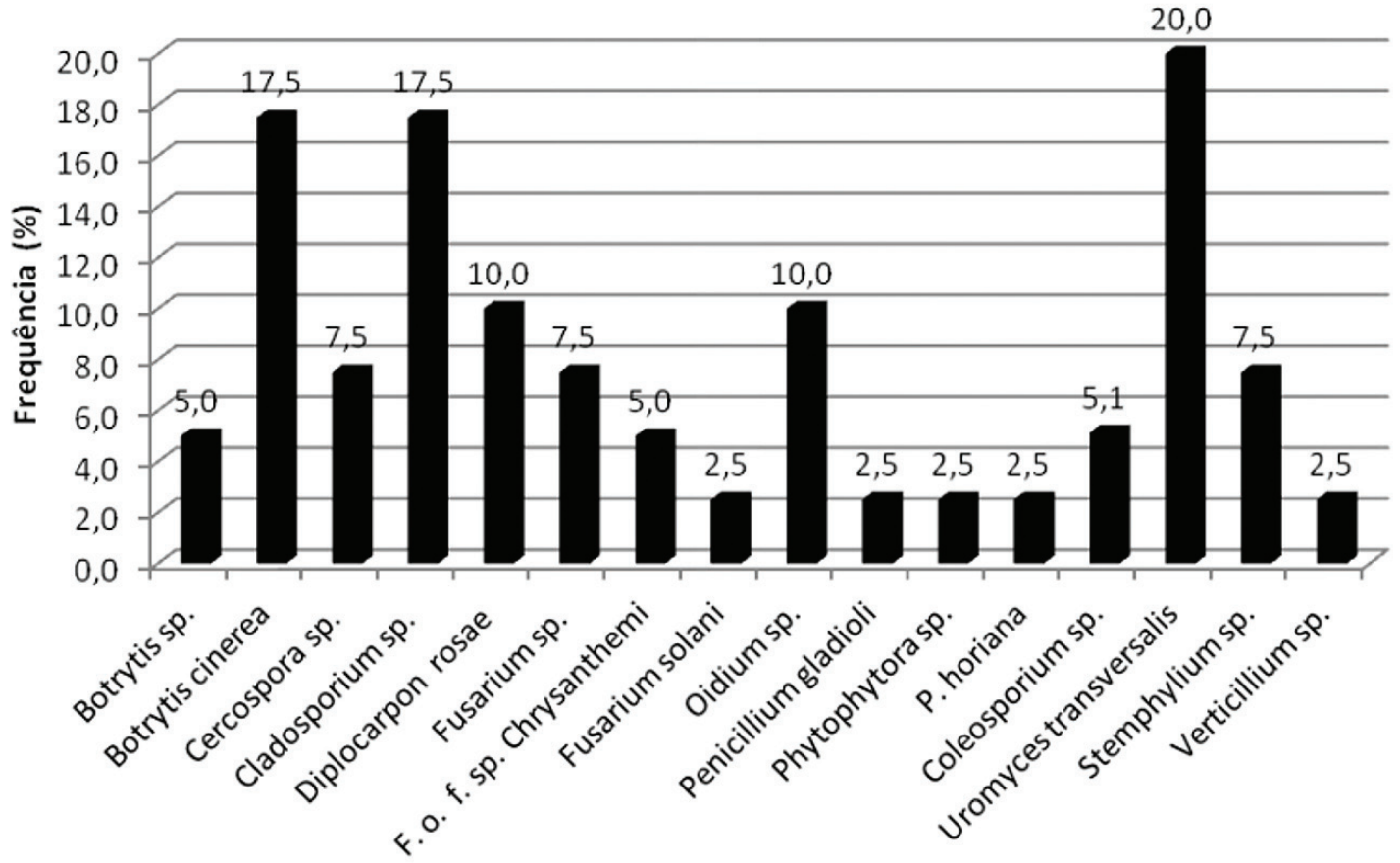

Especiés fungicas

Figura 2. Frequência de fungos em plantas ornamentais temperadas detectados na Região Agreste pernambucana. 

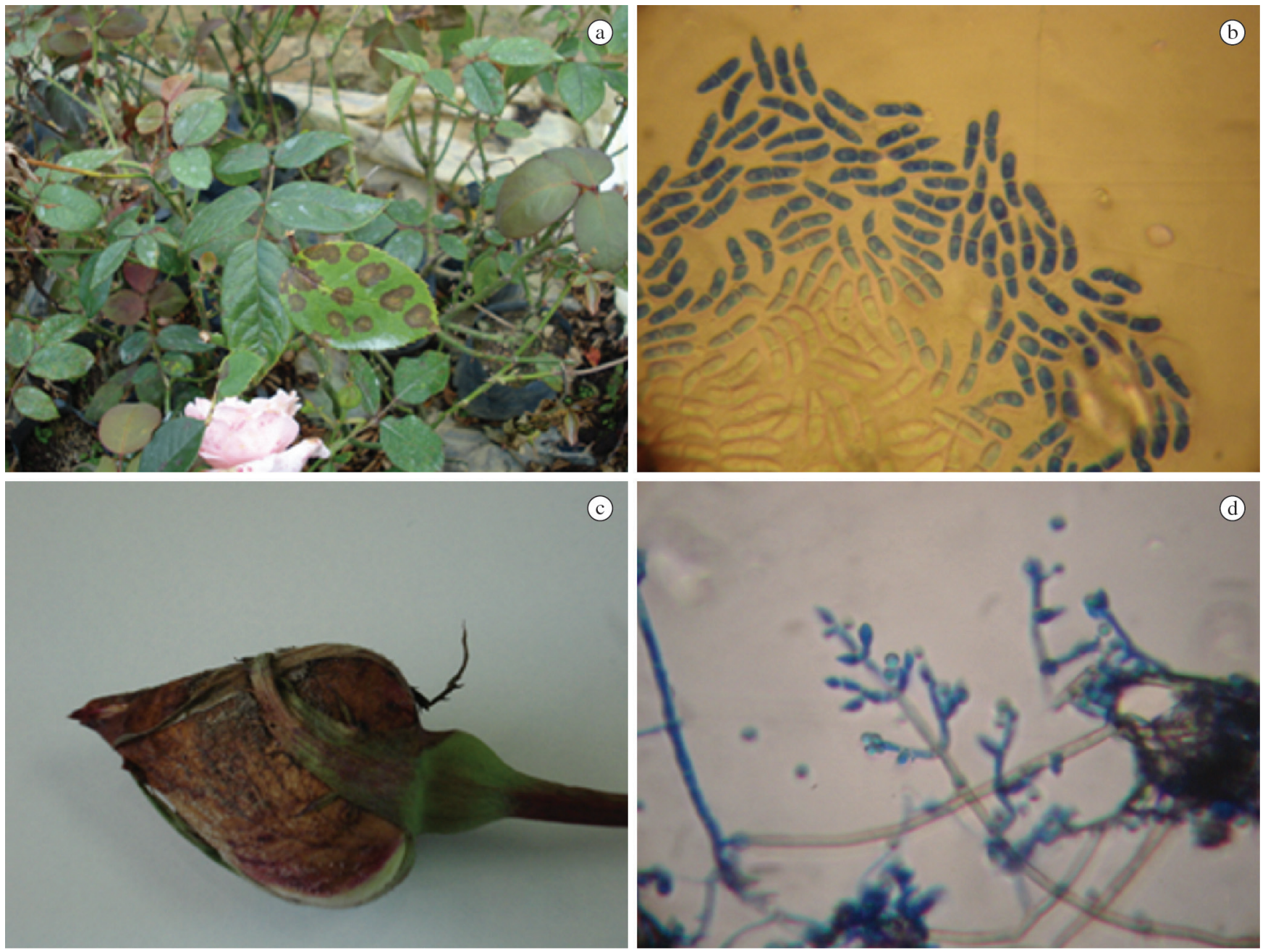

Figura 3. Principais doenças detectadas em roseira (Rosa spp.) na Região Agreste pernambucana: pinta-preta - sintoma foliar (a) e agente causal, Diplocarpon rosae (b); mofo-do-botão - sintoma (c) e agente causal, Botrytis cinerea (d).

Nas folhas, observa-se o desenvolvimento de manchas escuras, circulares e de bordos franjados, que podem coalescer e induzir a queda prematura das folhas (Figura 3) (PITTA; CARDOSO; CARDOSO, 1989; MARCHANT et al.,1998).

A ferrugem-amarela do gladíolo, causada por $U$. transversalis, é uma das principais doenças desta cultura, sendo considerada uma praga quarentenária na Europa e nos Estados unidos da América (PETERSON; BERNER, 2009). De acordo com o levantamento realizado na Região Agreste, verificou-se que as propriedades que cultivavam gladíolo apresentavam alta incidência da doença (Figura 4). Em campo, foram constatadas, em plantas doentes, baixas qualidades fisiológica e sanitária das flores, concordando com Pitta, Cardoso e Cardoso (1989), que também observaram, em plantas severamente afetadas, a produção de flores de qualidade inferior, cujos cormos não chegavam à maturação.

Nas áreas de cultivo de crisântemo, observou-se alta incidência do patógeno $P$. horiana, agente causal da ferrugem-branca. No Brasil, esta doença é considerada a mais importante da cultura do crisântemo (FREITAS et al., 1997; FREIRE; VIANA; LIMA, 2002). Inicialmente, os sintomas apresentam-se na forma de pequenas manchas de cor branco-amarelada na face adaxial das folhas, tornando-se posteriormente marrom-escura na parte central das lesões. À medida que a infecção progride, surgem na face abaxial das folhas, nas áreas correspondentes às manchas amareladas, pústulas salientes, esbranquiçadas a rosadas, cerosas, circulares e proeminentes, que consistem nas estruturas reprodutivas do patógeno (Figura 5). Quando ocorre a coalescência das pústulas, as folhas podem secar e cair, reduzindo drasticamente a área fotossintetizante da planta (FREITAS et al., 1997). De acordo com Norman et al. (1996), a doença diminui sensivelmente a quantidade e a qualidade das flores produzidas, e as perdas variam com a suscetibilidade da variedade e do estádio de desenvolvimento das plantas.

De acordo com a literatura, os fungos geralmente observados no cultivo de gérbera são Erysiphe cichoracearum; Oidium sp.; Alternaria sp.; Cercospora gerberae; Botrytis cinérea; Albugo tragopogonis; Capnodium sp.; Fusarium oxysporum; Pythium sp., e Phytophthora sp. (PITTA; CARDOSO; CARDOSO, 1989; APARECIDO; TOFOLI; COUTINHO, 2007; FERRONATO; LIMA NETO; TOMAZ, 2008). No 

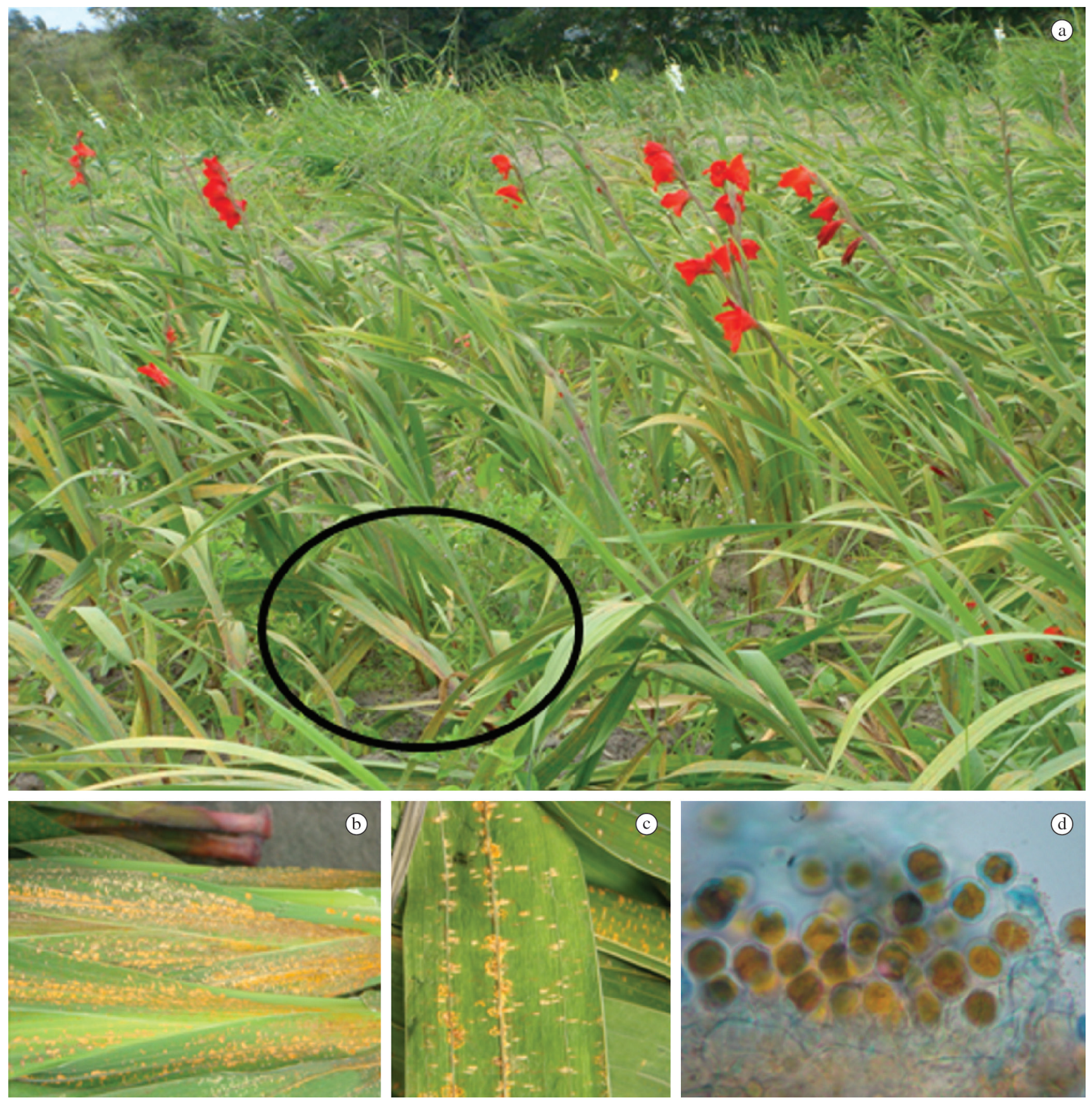

Figura 4. Sintomas foliares (a, b, c) da ferrugem do gladíolo (Gladiolus spp.) e os sinais do agente causal, Uromyces transversalis (d).

entanto, neste levantamento, foram detectados apenas os patógenos: Cercospora sp., Stemphylium sp. e Oidium sp., destacando-se este último com maior incidência, em que as plantas apresentavam crescimento micelial cinza esbranquiçado na parte adaxial da folha, chegando a recobrir todo o limbo foliar em estágios mais avançados (Figura 6).

Com relação à cultura do tango, poucos são os relatos sobre doenças fúngicas no Brasil. Sclerotium rolfsii e Coleosporium solidaginis ocorrem em campos de tango na China e em diferentes municípios do Ceará, respectivamente (FREIRE; MOSCA, 2009; TANG et al., 2010). As plantas de tango apresentavam lesões na superfície foliar, subcirculares e cloróticas, tornando-se marrom-acinzentadas na parte adaxial da folha, causadas por Coleosporium sp. em área de cultivo de tango, na cidade de Gravatá (Figura 7).

A roseira e o crisântemo apresentaram maior diversidade fúngica. O fungo Uromyces transversalis foi mais frequente, seguido de Botrytis cinerea e Cladosporium sp. Devido à importância das flores temperadas para a Região Agreste Pernambucana, torna-se necessário dar continuidade ao levantamento de doenças, visando a prover informações sobre a importância de cada patossistema, a fim de elaborar medidas de manejo/controle adequadas às necessidades dos produtores da região. 


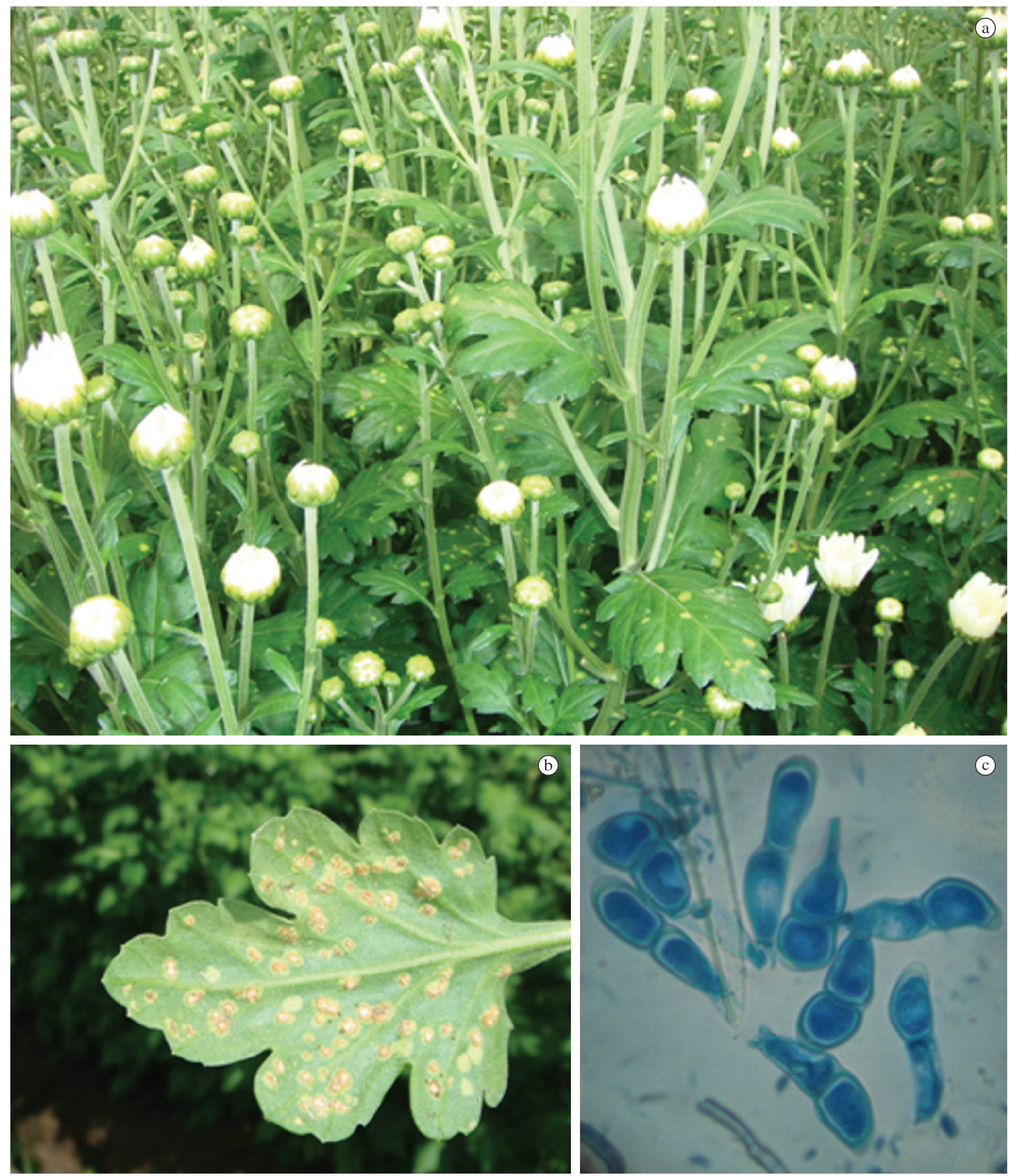

Figura 5. Sintomas foliares (a, b) da ferrugem-branca do crisântemo (Chrysanthemum spp.) e os sinais do agente causal, Puccinia horiana (c). 


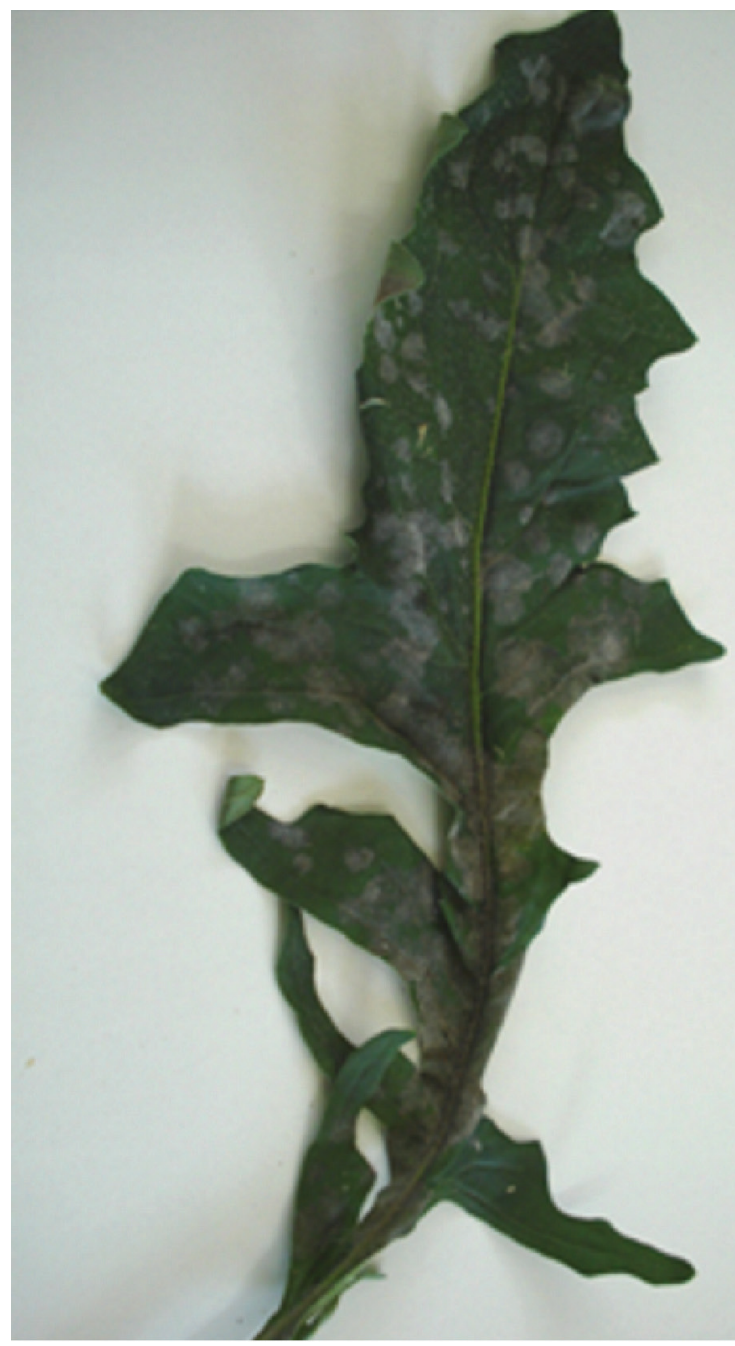

(a)
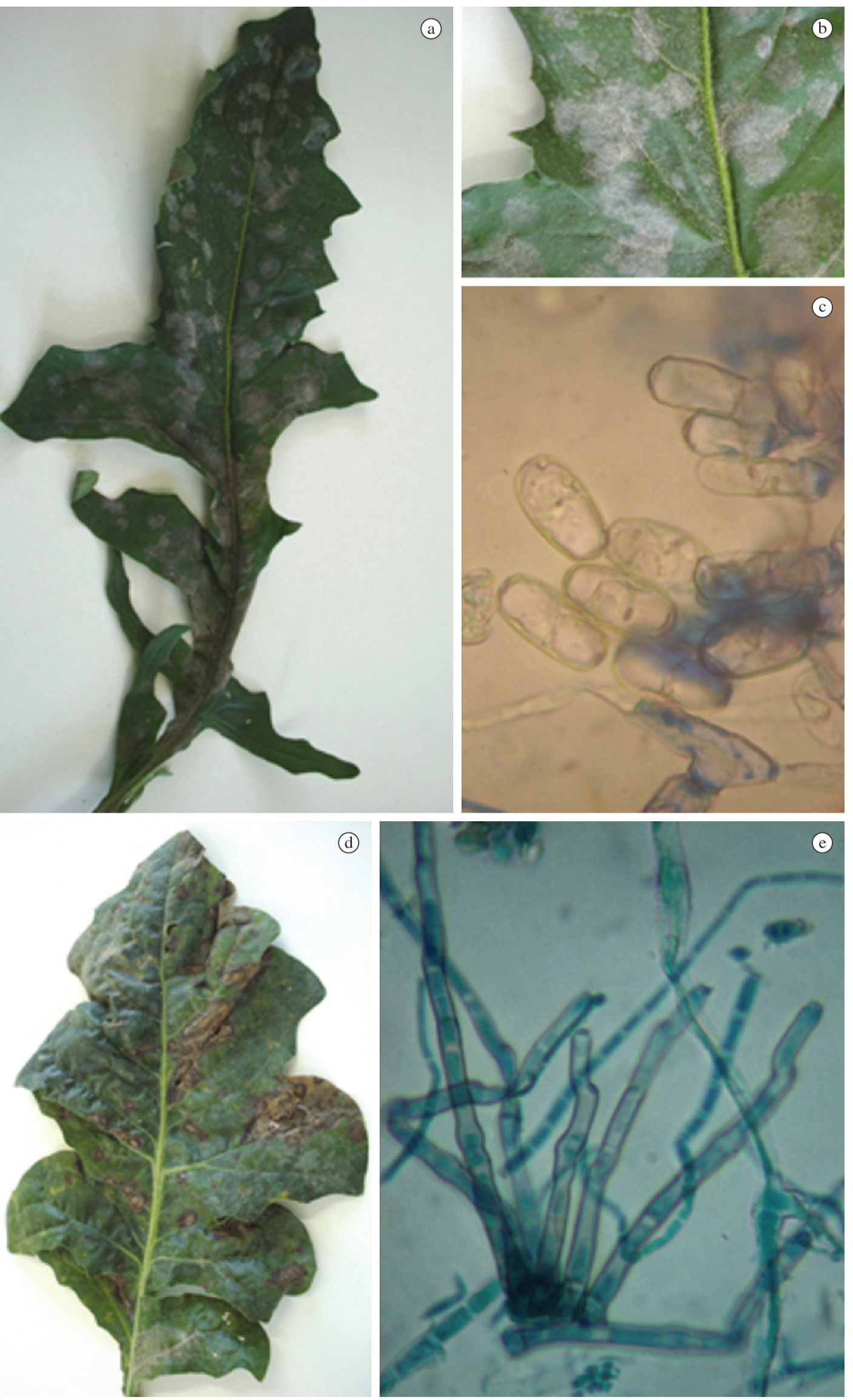

Figura 6. Doenças detectadas em Gerbera spp. na Região Agreste pernambucana: mofo-branco - sintoma foliar (a, b) e agente causal, Oidium spp. (c); mancha-de-cercospora - sintoma (d) e agente causal, Cercospora sp. (e). 

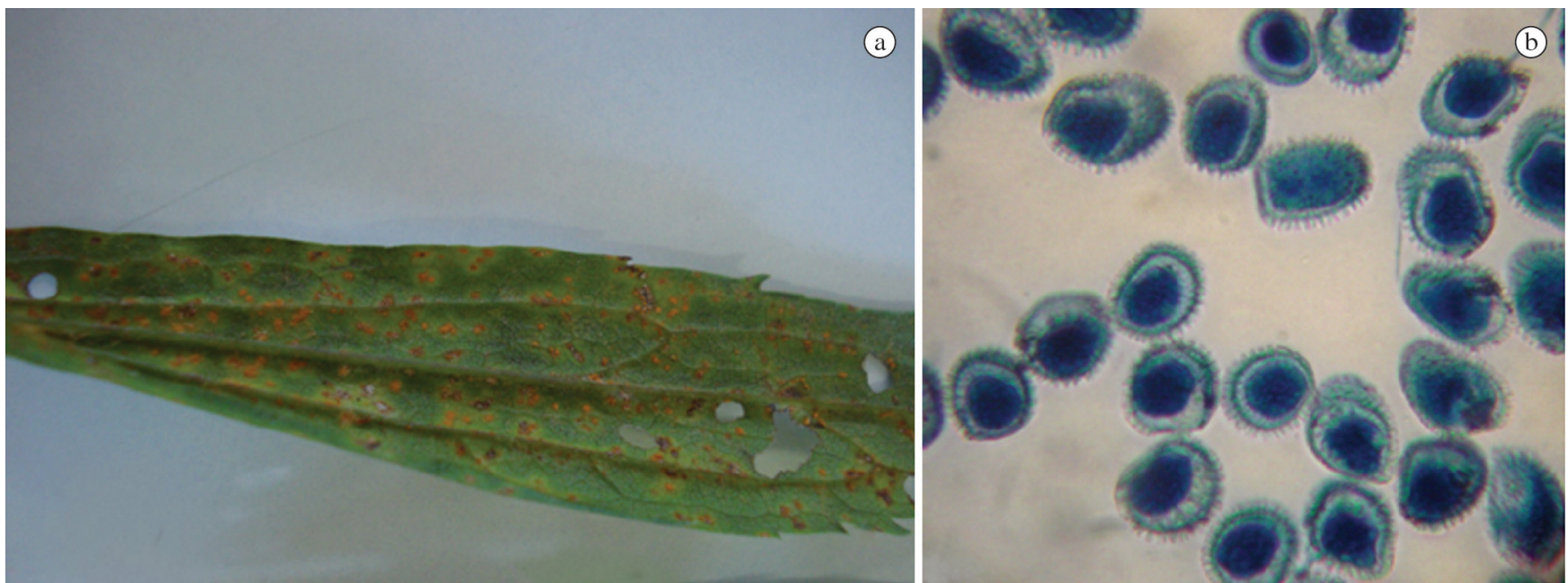

Figura 7. Sintomas foliares (a) da ferrugem do tango (Solidago canadensis) e os sinais do agente causal, Coleosporium sp. (b).

\section{REFERÊNCIAS}

ALEXOPOULOS, C. J.; MIMS, C. W.; BLACKWELL, M. Introductory mycology. 4th ed. New York: John Wiley \& Sons, 1996. $868 \mathrm{p}$.

APARECIDO, C. C.; TOFOLI, J. G.; COUTINHO, L. N. Doenças fúngicas e controle. In: ALEXANDRE, M. A. V.; DUARTE, L. M. L. Aspectos fitopatológicos de plantas ornamentais. São Paulo: Instituto Biológico de São Paulo, 2007. p. 23-27. (Boletim, n. 20).

BRAINER, M. S. C. P.; OLIVEIRA, A. A. P. Floricultura: perfil da atividade no nordeste brasileiro. Fortaleza: Banco do Nordeste, 2007. 351 p. (Documentos do ETENE, n. 17).

BARNET, H. L.; HUNTER, B. B. Illustrated genera of imperfect fungi. 1th ed. Minnesota: Burguess Publising, 1972. $241 \mathrm{p}$.

FERRONATO, M. L.; LIMA NETO, V. C.; TOMAZ, R. Doenças em cultivos de gérbera no Estado do Paraná. Scientia Agraria, Curitiba, v. 9, n. 4, p. 481-489, 2008.

FREIRE, F. C. O.; MOSCA, J. L. Patógenos associados a doenças de plantas ornamentais no Estado do Ceará. Revista Brasileira de Horticultura Ornamental, Campinas, v. 15, n. 1, p. 83-89, 2009.

FREIRE, F. C. O.; VIANA, F. M. P.; LIMA, R. C. A. Ocorrência da ferrugem-branca-do-crisântemo no Estado do Ceará. Fortaleza: Embrapa Agroindústria Tropical, 2002. 2 p. (Comunicado Técnico, n. 75).

FREITAS, J. C. et al. Controle da ferrugem branca do crisântemo (Puccinia horiana) em condições de casas de vegetação com diferentes mantas de cobertura. Summa Phytopathologica, Jaboticabal, v. 23, n. 3/4, p. 268-271, 1997.

INSTITUTO BRASILEIRO DE FLORICULTURA - IBRAFLOR. Uma visão do mercado de flores. Campinas, 2011. Disponível em: <http://www.ibraflor.com>. Acesso em: 04 ago. 2012.

LANDGRAF, P. R. C.; PAIVA, P. D. O. Produção de mudas para jardim no estado de Minas Gerais. Ciências e Agrotecnologia, Lavras, v. 33, n. 1, p. 127-131, 2009.
MARCHANT, R. et al. Expression of a chitinase transgene in rose (Rosa hybrida L.) reduces development of blackspot disease (Diplocarpon rosae Wolf). Molecular Breeding, v. 4, n. 3, p. 187 194, 1998. http://dx.doi.org/10.1023/A:1009642707505

MEDEIROS, F. O.; FAVERO, L. A.; PEDROSA FILHO, M. X. Estudo da cadeia produtiva de flores: município de Gravatá. Fortaleza, 2006. Disponível em: <www.sober.org.br>. Acesso em: 04 ago. 2012.

MENEZES, M.; ASSIS, S M. P. Guia prático para fungos fitopatogênicos. 2. ed. Recife: Imprensa Universitária, 2004. 187 p.

NELSON, P. E.; TOUSSOUN, T. A.; MARASAS, W. F. O. Fusarium species: an illustrated manual for Identification. Pennsylvania: The Pennsylvania State University, 1983. 193 p.

NORMAN, M. T. et al. Nivel de daño causado por Puccinia horiana P. Henn. en crisantemo (Dendrathema grandiflora Tzvelev). Fitopatología, Lima, v. 31, n. 2, p. 133-139, 1996.

PETERSON, G. L.; BERNER, D. K. Effects of temperature and humidity on the survival of urediniospores of gladiolus rust (Uromyces transversalis). European Journal of Plant Pathology, Netherlands, v. 125, n. 3, p. 509-513, 2009. http://dx.doi. org/10.1007/s10658-009-9492-5

PITTA, G. P. B. Flores e plantas ornamentais para exportação: aspectos fitossanitários. Brasília: EMBRAPA, 1995. 50 p. (Publicações técnicas FRUPEX, n. 17).

PITTA, G. P. B.; CARDOSO, R. M. C.; CARDOSO, E. J. B. Doenças das plantas ornamentais. São Paulo: Instituto Brasileiro do Livro Científico, 1989. 186 p.

SANTOS, A. Produção de flores de corte temperada. Salvador: Sebrae Bahia, 2009. 40 p.

TANG, W. et al. First Report of Southern Blight on Canadian Goldenrod (Solidago canadensis) caused by Sclerotium rolfsii in China. Plant Disease, St. Paul, v. 94, n. 9, p. 1172, 2010.

SIVANESAN, A. Graminicolous species of Bipolareis, Curvularia, Drechslera, Exserohilum and their teleomorphs. 1 th ed. Surrey: C.A.B International Mycological Institute, 1987. 261 p. 